reducing the amount of fat and carbohydrates. Then the question of the proteid element comes up. There is no doubt in this class of cases but that the proteid element must be higher than seventy grams; one cannot produce an improvement in metabolisin without more proteid; hence we must give it to furnish the best nutrition for the cells of the body. Consequently in all these cardiorenal cases it will be found advisable to raise the amount of proteids higher than physicians as a rule recommend. This may be considered a little off from the subject of the paper, but it is such a common thing to find the renal and curdine cases mixed that it is well to consider them.

Dr. PHilip S. RoY, Washington, D. C.: I have used Dr. Arnold's charts regularly. As to the question of fats and carbohydrates overlouding the system and the metabolism becoming deranged as a consequence thereof, as mentioned by Dr. Smith, I liave not found that the case if Dr. Arnold's plan be fol. lowed. When one wishes to lessen the number of carboliydrate calories, he can replace these calories with fat. Three pints of milk with a pint of cream and one ounce of butter equals about 2,000 calories. This will give all the energy needed. $1 \mathrm{am}$ in accord with the statement that the proteids in disense of the kidney should not be above 50 grams daily.

Dr. H. D. AnNold, Boston: I am glad that Dr. Smith mentioned the cardiorenal cases in which the cardiac end predominates. The problem here is somewhat different, in that the nower of the kidneys to eliminate nitrogenous material is less seriously impaired. Greater liberality in the use of protein food may be allowed, yet even in these cases there is no neessity for large amounts. I think that 50 grams of protein are enough for the purposes of tissue building, including the heart. It is of grent importance that there should be an abundant amount of nutrition-a sufficiently high caloric value to the diet-but beyond the amount of protein needed for tissuebuilding, this nutriment is just as well, if not better, derived from the other foodstuffs. Often, however, our plan must be modified because of questions of digestion and assimilation. Some people cannot digest fats well, and others have difficulty with the carbohydrates. I would not be understood as maintaining that we must always give the number of calories which are indicated by theoretical ealculations. Often we find a patient will maintain weight and strength, and may even gain, on 1,500 calories' when 2,000 or more are demanded theoret. ically. If such is the case it is a mistake to force the patient to take the larger amount.

The only credit I feel that I am entitled to in this work is in getting our knowledge in dietetics into a simple, practical form for application in ordinary practice. There is nothing in it that is new or that has not been utilized by the laboratory workers in metabolism experiments for years. But the data have been too complicated for use in ordinary cases and have not been easily available. If we can upply these principles to ordinary patients we shall plan diets with far more intelligence than we have done in the past.

Health and Sanitation in Cuba.-Reporting the result of an inspection trip over the Island of Cuba (Sanidad y Beneficencia, April, 1010, p. 305), Dr. Manuel Varona Suarez, Secretury of Health and Charities, says that there did not exist $n$ single case of quarantinable disease with the exception of leprosy, and that his country was on a level with the henlthiest communities in the world. He also usserts that should such a disease enter the country the effeient sanitary orgunization of the island would be able to ward of the threatening dunger. He feels that the national health department is ellicient, but regrets that he cannot say as much for the sanitary service in the municipalities, for he found with a few exceptions that vaccination was neglected, that the public slaughter-houses were in a shameful condition, and that the cemeteries were almost as much neglected: Two great obstacles to efficient sanitation were lack of water-supplies and sewerage systems. His inspection convinced him of the urgent necessity of establishing dispensaries and sanatoriums at appropriate sites in the various provinces and of founding hospitals and special wards for the care of the large consumptive population which lacks resources to protect itself against the disease and which constitutes the chief fuctor in its propugation.

\section{APPENDICITIS IN CHILDHOOD}

WITI A REPORT OF 500 CASES *

H. C. DEAVER, M.D.

Professor of Surgery, Woman's Medical College of Pennsylvania: Visiting Surgeon to Eplscopal, St. Agnes' and Stetson Hospttals, and Culldren's I-Iospital of the Mary J. Drexel Home

PIIILADELPIIIA

This paper is based on an analysis of 500 cases in which I operated at the Children's Hospital of the Mary $J$. Drexel Home, and on a review of the more recent literature.

Appendicitis in childhood, characterized as it is by subtle and insidious onset, rapid progress and obscurity of symptoms, is a disease of the most profound importance, and it well merits more attention and study than has hitherto been bestowed on it.

The earliest case of appendicitis was reported by Dixon, ${ }^{1}$ and occurred in a baby, aged 24 days, which was premature at the eighth month. The appendix was gangrenous and formed, with part of the cecum and ilcum, the contents of $\dot{a}$ sac of a strangulated inguinal hernia. Since the appendix was adherent to the sac, Dixon held it responsible for the descent of the ileum and cecum. A very similar case is reported by Lilienthal." Other cases of infantile appendicitis are reported by Bamberg, ${ }^{3}$ in a child, aged 5 weeks; by Dennis and Goyens, in two infants, aged 6 weeks, and by Blumer and Shaw, in one, aged 7 weeks. Berkholz reports four cases in infunts, aged $12,15,17$ and 19 months, respectively, while Schellong ${ }^{5}$ met a case in an infant, aged 21 months. Alsberg gives as his youngest patient a baby, aged 6 months, while Springer ${ }^{7}$ has seen none younger than 3 years. My youngest patient was 21 months old. Mayet (cited by Springer) collected reports of nine cases of appendicitis in infants. In 1,000 cases $\mathrm{McCosh}{ }^{8}$ found 1.7 per cent. in children up to 5 years of age. My statistics, however, place the frequency in the first five years at about 8 per cent. This frequency in the first five years of life will probably be diminished under more refined diagnoses. Churchmann ${ }^{2}$ thinks that infantile appendicitis deserves separate consideration from that occurring later in childhood, stating, with much truth, that the surgical problem of infantile appendicitis is that of diagnosis, and that the difficulty of diagnosis keeps up the mortality. So, also, von Brimann ${ }^{10}$ asserts that the danger of appendicitis is greater in the first ycars of life than later, and gives a 50 per cent. mortality in all infants under 5 years of age that were present in a series of 117 cases in children. In those from 6 to 10 years of age, inclusive, the frequency jumps from 8 per cent. to 36 per cent., finally reaching 56 per cent. in those between the ages of 11 and 15 years.

As to sex, males predominate. Riedel ${ }^{11}$ found that of 1,532 putients 955 were males and $57 \%$ females. My series showed 315 males and 185 females.

* Rend in the Section on Surgery of the American Medical Asso cation, at the Sixty-first Annual Session, at St. Louls, June, 1010 - lor leasons of space, the tuble of cases is omitted. It nppear. in the 'Transuctlons of the section and in the anthor's reprints.

1. Ilxon: Ann. Surp, 1908, xlvil, 57.

2. Lillenthal, Howard: THE JoulwaL A. M. A., Aug. 20, 1008, p. $7 \overline{5} 4$.

3. I3amberg: Inaug. Dlss., Leipslc, 1005 .

4. Berkholz: Monntschr. f. Kinderh., Ixxxvill, 133

5. Schellong: Med. Iriln., 1908, Iv, 722

6. Alsber. Arch. f. Kinderh., 1009, I, 252

7. Springer: l'ray, med. Wchnschr., 1009 xxxiv, 89

8. MeCosh, A. J.: Appendicltis in Children, THe Joursal A.

M. A., Sept. 24,1009 , p. 853

9." Churchmann : Bull. Johns Hopkins Hosp. 1909, xx, 31.

10. v. Bramunu: Deutsch. med. Wehnschr., 1909, xxxv, 1501.

11. Rledel: Munchen. wed. W chnschr., 1907, IV, 2300 
The microscopic pathology of acute appendicitis has been carefully studied by Alsberg, ${ }^{6}$ wlo emphasizes the importance of fixing the appendix in 0.8 per cent. formaldeliyd solution immediately after its severance from the cccum. The most important changes, of course, are in the mucosa, but the other coats act in sympathy, as the inflammation increases in intensity from the center toward the periphery. In the mucosa the epithelium is desquamated, often eroded and extensively destroyed, and hemorrhages are frequent. The solitary lymphnodules are enlarged, thickened and studded with polymorphonuclear eosinophils. Alsberg warns against mistaking the exceptionally well-developed nodules of children beyond 2 years of age, especially when cut oblique, for inflammatory changes. The submucosa and sometimes the muscular coat is edematous and the blood and lymph-vessels distended and choked with leukocytes. 'Tlise serosa is congested and often covered with white fibrin. Ulceration may extend through to the serosa, producing appendicitis granulosa of Riedel, which involves, by predilection, the hip.

In chronic appendicitis also the principal changes are found in the mucosa, in which the epithelium and mucous glands are destroyed and the lymph-nodules atrophied, while contractions may obliterate the entire length of the lumen, or only one part of it. Stenosis near the base of the appendix leads to the formation of hydrops or empyema, and, if near the tip, produces a globular swelling, which, however, causes little or no danger. Adhesions, more or less extensive, may be connected with other organs more remote from the ileocecal region than in adults, because of the greater length of the appendix in children, which compared to that of the large intestine, is, according to Ribbert, 1.1 in new-born chilclren and 1.2 in adults. This circumstance accounts for many mistaken diagnoses, Schellong ${ }^{\mathbb{b}}$ reporting a case in which the appendix ran transversely behind the bladder to the left and set up a left-sided appendicitis. Riedel ${ }^{11}$ states that strictures are relatively rare in children, because a long time is required for their formation. He places their frequency in adults at 26.5 per cent. and in children at 8.7 per cent. Fecal concretions, on the other hand, are relatively common, Springer ${ }^{7}$ having found them in 59 per cent. of acute cases and in 20 per cent. of chronic. They are even more frequent than in adults, in the proportion, according to Riedel, of 39 per cent. in children and 27.7 per cent. in adults. The same author states that the worst attacks are associated with suppurating fecal concretions. It is interesting to observe that Tow found meconium in the appendix of a 5-month fetus.

Often, the regional lymph-nodules are swollen, indurated and inflamed, and Comby ${ }^{12}$ regards them as "witnesses of infectious processes of which appendicitis is the stage." Churchmann ${ }^{0}$ states that the pathology of appendicitis in children is distinguished from that of adult life by the tendency to early perforation and the frequency of spreading peritonitis, and Sloan ${ }^{13}$ observes that the undeveloped omentum affords less protection against rapidly spreading peritonitis.

The predisposing causes of appendicitis are said to be infectious disease, family disposition, dental caries and mechanical irritation. Of the infectious and contagious diseases, enteric fever, scarlatina, influenza, mumps, pertussis and chicken-pox, have been mentioned. Enteric

12. Comby : Bull. méd., Parls, 1ภ08. xxj, 5:35

13. Sloan: Eclect. Med. Jour., Cincinnatl, $1900,1 \times 1 \times, 372$ fever and intestinal catarrh certainly produce congestion of the appendix, which, with superficial loss of epithelium, may prepare the way for infection of the deeper layers. As to scarlatina, Springer states that Ganghofer, in twenty years' experience with scarlet fever, did not observe acute appendicitis in a single instance. Epidemics of influenza often leave in thcir wake severe acute attacks of appendicitis; certainly, influenza readily affects lymphoid organs. Chicken-pox was more than likely the cause of appendicitis in Schellong's case. 'The etiologic status of nasopharyngeal troubles, tonsillitis, adenoids, cervical adenopathies and otitis media, is problematic, as the path by which the exciting cause of these conditions reaches the appendix is somewhat obscure, unless it is assumed to be hematogenous. Sloan ${ }^{13}$ states that the period of greatest development and activity of the lymphoid tissues corresponds to the period of greatest incidence of appendicitis. Family disposition is emphasized by the French, and may be accounted for by the irregular mode of life among poor families, so that neglect, improper feeding and insufficient medical attention may bring about appendicitis as well in one child of a family as in another.

Jackson ${ }^{14}$ presents eleven arguments why dental curics should cause appendicitis, the most striking of which are that infants suffer rarely and that the civilized have both dental caries and appendicitis, while the uncivilized have good teeth, and no appendicitis. Teeth, examined by Alsberg in nine children with appendicitis, were carions, and partly absent in six and normal in three. Mechanical irritation may be caused by errors of diet and foreign bodies. Errors of diet, though undoubtedly responsible for recurrences in adults, are probably only remotely connected with acute appendicitis. Springer has noticed no increase in the frequency of acute appendicitis when the fruit season is at its height. Fecal concretions and other foreign bodies may irritate the appendix enough to permit the entrance of bacteria through epithelial abrasions, but, on the contrary, they may lie dormant for a long time and, not rarely, throughout life. Alsberg found two bits of enamel in an acutely inflamed appendix. To intestinal worms, by their frequency in childhood, might be ascribed a causative rôle. In large numbers (as, for example, 80 oxyuris in an appendix extirpated by Hippius-Levinsohn, cited by Springer) they could block the lumen of the appendix, cause colic, and injure the mucosa superficially by trauma and by the elaboration of toxins. The exciting cause of appendicitis is, of course, bacterial, and usually Bacillus coli communis, which is ever alest to invade the walls of the appendix through a locus minoris resistentiae offered by any of the predisposing causes. Other pyogenic organisms may act alone or in conjunction with $B$. coli.

The symptoms of acute appendicitis in infants are unquestionably scanty, irregular and misleading, and it undoubtedly follows that infantile appendicitis is more frequent than is generally believed, or than statistics show. Thus, at autopsy on a 2-weeks-old infant that died of severe acute enteritis, Deiss (cited by Soltmann) found acute appendicitis with serofibrinous peritonitis, without having produced any clinical symptoms, and concludes from this that such findings in infants, even when less severe, are frequent. So, too, Churchmann states that appendicitis of the severest type may exist without one of the classic symptoms, and that even a general peritonitis may develop under observation.

\footnotetext{
14. Jackson: Australaslan Med. Cong. Tr., 1909, 1, 1859.
} 
In older children, on the contrary, symptoms reach the other extreme, and acute attacks, even more regularly than in adults, occur suddenly and with very stormy symptoms. There are severe pains which localize about the navel, shortly followed by vomiting, rigidity, more or less extensive, and abdominal distention. The temperature is usually higher than in adults and the pulse more frequent. On the whole, these children give the impression of being seriously ill, lying on their backs with legs drawn up, or curled up on their side, writhing from pain. It must be remembered that the child may be mentally incapable of accurately locating the pain, often pointing to various parts of the abdomen as the place of greatest intensity. Voluntary rigidity is common in children, owing to fear. Hyperpyrexia is an attribute of childhood, and the rapid pulse is due in part to the hyperpyrexia, and in part to the restlessness of the child. Thus, it is evident that the reaction of the whole organism is more active in childhood than later.

In chronic appendicitis the whole organism may be affected by the presence of a chronic focus of infection. The troubles are chiefly digestive. The appetite is capricious and varies from day to day. The tongue is coated and the breath bad. Digestion is slow and dyspepsia marked by flatulence and epigastric swelling after meals. Constipation is habitual and obstinate. Such disturbance may interfere with nutrition even to the extent of emaciation. The face may be thin, pale and sallow, and there may be black circles about the eves. On the other hand, sufferers from chronic appendicitis may have rosy cheeks and a generally healthy condition. There may be circulatory disturbances, as pallor and blushing of the face, cold hands and feet, and cardiac palpitation and dyspnea on exertion. Secondary anemia, with a murmur at the base of the heart may exist, and fainting may occur. Appendiceal neurasthenia may render children dull and silent and "friends of solitude and repose."

The diagnosis of appendicitis in infancy and childhood should be made easy by the epigram: "All cases of abdominal trouble in children are appendicitis until proved otherwise." With this proviso, there should follow a systematic examination of all organs. In infancy it is unquestionably difficult, yet usually capable of being established: In this solution it must be borne in mind that the younger the child, the more deeply the appendix lies in the pelvis, owing, according to Selter, to the deep position of the cecum in the pelvic fossa. Hence, it is conccivable that bladder symptoms may monopolize the attention of the examiner, there being cloudy urine from edema of the bladder, tenesmus, and even retention from direct irritation of the bladder wall. Many cases have been reported in which urinary symptoms predominated. Churchmann writes that all urinary symptoms in childhood suggest the possibility of appendicitis. For the same reason pelvic abscesses are common, and may simulate abscesses from other causes, so that the same author states that in infants with apparent hip-joint disense, particnlarly if the thigh be flexed, the same possibility should be kept in mind. It is obvious then that every possible means of reaching in and about the right iliac region must be employed. The simple procedure of catheterizing the bladder may go a long way toward clearing up a doubtful case, and evacuating the phantom pelvic abscess.

By far one of the most important procedures in children is rectal palpation, and this must never be neg- lected. Churchman states that palpable resistance on the right side by rectal examination is one of the most frequent findings, and Selter calls it absolutely constant. In Schellong's case, the symptoms were characteristic of rectal abscess, including fever, rectal tenesmus and frequent small slimy stools. Rectal examination revealed within half a finger's length an abscess which protruded from above and to the right toward the rectum. Doubtless this rectal palpation has been the sole element of correct diagnosis in numerous cases, including two of my own. 'Tenderness at MclBurney's point, when present, is almost pathognomonic, but the wandering appendices of clildhood may carry their tenderness elsewhere. Thus, tenderness may be greater on the left side than on the right, as when the appendix is in the pelvis. Other signs, more applicable to older children, are hyperesthesia of the skin, and the fact that sudden removal of the palpating finger-tips from the point of greatest tenderness is more painful than the finger-tips themselves. Carstens's recommends palpatory percussion. Flexion of the right thigh on the ablonen is likewise very suggestive. In chronic appendicitis the organ is more olten palpable than in adlults, and an analytic study of the symptoms, together with localization of the tenderness at or near MeBurney's point, usually establishes the diagnosis.

An appreciation of the difficulties of differential diagnosis may be had only by scanning the various and varying cases reported in the literature. Affections of the thoracic, abdominal and pelvic viscera, as well as of near-by joints, may enviously mimic the peculiar little ways of the appendix. The old question of pneumonia or appendicitis must be cautiously considered, particularly right-sided central pneumonia with but few physical signs. At the onset of right-sided croupous or central pneumonia, pain is often referred to the abdomen, and incriminates the appendix. This abdominal hyperesthesia may disappear by firm manual pressure, and the abdominal walls relax between respirations, which are very rapid. There may be herpes and cyanosis of the lips. In puzzling cases, careful observation usually clears the diagnosis within twenty-four hours. Cholelithiasis is rare in childhood, yet Alsberg mentions a typical gallstone attack in a 3-year-old clild, with the passage of gall-stones. Julien ${ }^{10}$ reports a case of perforative appendicitis with retrocecal abscess, which was diagnosed as hepatic colic. Pancreatitis, renal colic, and movable kidney are rare in childhood. Intestinal catarrh, especially when accompanied by colic, may seriously cloud the diagnosis because of pain, romiting, increased abdominal tension, fever and rapid pulse.

of the intestinal obstructions, intussusception may be distinguished by the tympanites, by paroyxsmal pain, by the discharge of bloody mucus from the anus, and by the late appearance of inflammatory peritoneal reaction, although if seen for the first time in the stage of general peritonitis, differentiation from appendiceal peritonitis is impossible, and in such cases operation is the safest procedure. Intussusception is of importance because of its frequency in childhood. The dense, sausage-shaped tumor, which slifts and varies in size, even to the extent of being reached by rectal palpation, as the intussuscipiens advances; may be helpful in diagnosis. Springer was led to the erroneous diagnosis of perforative appendicitis with peritonitis in a case which autopsy showed to be volvulus, caused by a lymphangioma in the mesentery

15. Carstens: Deutsch. med. Wchnschr., $100 \Omega$. p. 1692.

16. Julleu: Echo med. du Nord., 1007, xl, 859. 
of the small intestine. This case suggests the possibility of a congenital mesenteric cyst, such as I recently ${ }^{17}$ reported, likewise being confused with acute appendicitis. In one of my cases, a right ovarian cyst twisted on its pedicle, in a girl aged 12, simulated acute appendicitis. In girls, salpingitis and gonococcic peritonitis must be considered, and the presence of vaginal discharge or vulvovaginitis will be helpful, as well as rectal examination. Tuberculous peritonitis was mimicked by a case of appendicitis reported by Rubritius and Hermann (cited by Springer) from von Jaksch's clinic. Acute cystitis in small children, caused by the colon bacillus, gives rise to fever, pains about the navel and vomiting. Here urinalysis, which often must be made repentedly, suggests the diagnosis. Chronic appendicitis, by causing adhesions to the bladder, may be confused with cystitis. Lumbar abscess, such as may accompany Pott's disease, was diagnosed by Julien ${ }^{10}$ in Case 4 of his series, a girl aged 4 with appendiceal abscess, which was evacuated by lumbar incision. In right-sided hip-joint disease there is absence of inflammatory peritoneal reaction, presence of muscular contracture, and the demonstration of foci of diseased bone. Churchmann reports cases which simulated this as well as vesical calculus, intestinal obstruction, associated with roundworms, and even cerebrospinal meningitis. Diagnosis in cases treated medically must always be uncertain.

The prognosis of acute appendicitis is favorable, if the case is received early, and if the appendix is removed carly. If the patient is operated on within the first twenty-four hours, the mortality is practically nil. Beyond this time, in suppurating cases, the mortality rapidly rises and after the third or fourth day is nearly as unfavorable as it was favorable in the early stage. With the flight of time, thininer grows the hair that suspends the sword of Damocles. Moreover, the danger of acute appendicitis is greater in the first two years of life than later. In chronic appendicitis, while there is no immediate danger, yet an acute attack with perforative peritonitis is always to be foared. In fact, as Alsberg expresses it, "A person who has once recovered from an attack of appendicitis sits on a barrel of gunpowder."

As regards the value of the leukocyte count, I agree with Soltmann that the greater the leukocytosis, and the larger the relative percentage of polymorphonuclears, provided the temperature and the pulse are proportionate and not high, the more favorable the prognosis; while the lower the leukocytosis, with lower temperature and more frequent pulse, the more unfavorable and severe the course. He thinks that leukocytes here play a rôle similar to that which they play in the autolysis of the lungs in pneumonia, where a proteolytic ferment exerts a digestive action on the exudato.

'The ideal treatment will maintain the mortality at nil. This ideal will be attained only when all patients are operated on early. 'That early operation is the normal course to pursue is now conceded by the world's surgeons. It is true that more early cases are received than formerly. That is why the mortality is decreasing as the years roll on. But the desideratum is that all patients be received early. I believe that the fault is not so much with the medical profession as with the ignorance and prejudice of parents. How many patients do we receive, sick from three to seven days, with pus-Jaden abdomens, and the parents beseeching us to operate!

17. Deaver, H C.: Ann. Surg., 1909, xlix, 019.
The time to operate, then, is before the storm breaks, and while the noon-day quiet holds the hill. Twentyeight of the appendices in my series were ballooned with pus, and on the point of exploding, when removed. Such an organ, like Vesuvius, threatens the entire per'itoneal cavity. A unique feature of appendicitis, up to and during this stage, is that the entire area of acute inflammation and phlegmon can be removed with nothing but benefit to the patient. Where else in the body is such a thing possible? Can a digit, the seat of a felon, be amputated with propriety? Can a pyosalpinx be removed with the same disregard for the value of the organ? Can even a surface phlegmon, as a carbuncle, be removed in toto in a similarly satisfactory manner? Inconceivable! Here, then, is an organ which, together with the disease that has attacked it, can be ablated without depriving the patient of an organ or tissue of any recognized value.

In cases in which there is a localizing abscess, with diffuse peritonitis, general abdominal tenderness, with more or less distention and bilateral rigidity, moderately high temperature and rapid pulse, with a jow leukocyte count and a large percentage of polymorphonuclears, it is best to defer operation. With the ebbing of the tide, there is often revealed a mass stranded on the pelvic shelf, an indication that the omentum and coils of intestine have had time to assemble and form a barrier to the pus. With the evacuation of the abscess, recovery is practically assured. In twenty of my cases I waited from two to twelve days before operating.

Such cases are managed very much the same as cases of acute pyosalpinx. Rest in bed, ice-packs to the abdomen, the Fowler position, gastric lavage, rectal instillations of saline solution and no water, no nourishment by mouth, no purgatives, no opium.

Opium clouds the symptoms and makes the diagnosis more difficult. By favoring tympanites, it interferes with palpation and percussion, and, by diminishing or removing pain, it makes severe cases assume a more benign aspect. It also retards the defensive activities of the leukocytes. Purgatives must be withheld absolutely. This statement cannot be made too strong. The majority of badly progressing cases of appendicitis have been treated with purgatives and the most unfavorable turn often dates directly from the time of their administration. Cases have been reported in which purgatives have produced perforation. As one writer expresses it, "First purgatives, then death." Cathartics must never be given unless it is absolutely certain that appendicitis is absent. By increasing pexistalsis, they interfere with the localizing process, and in the presence of perforation, increase fecal extravasation. If spontaneous defecation does not occur after the most acute symptoms have subsided, it may be assisted by small, lightly injected enemas of soap suds or oil, or by suppositories.

I wish it clearly understood that I employ non-operative treatment only in cases with localizing abscess with diffuse peritonitis. To treat early intra-appendiceal appendicitis medically is a hazardous venture; as well might one tie a halter about the little patient's neck. It is like the game of heads I win, tails you lose. Medical treatment should have no more place in the treatment of these early cases than it has in hare-lip or cleft palate. Its mortality is twice that of the operative, and in cases of recovery it is difficult to convince the parents of the 
necessity of interval operation. Furthermore, when recurrence does occur, surgical help may not be at hand.

Operation is even more suitable for children than for adults, since their kidneys and cardiovascular system have not suffered through alcohol or age, and hypostatic pneumonia seldom occurs. In suppurative cases the appendix may be removed when it lies free or presents conspicuously in the wall of the abscess. On the other hand, when the abscess is large and the appendix not directly visible, and when its removal necessitates extensive disseverance of adhesions, it should not be disturbed, because of the probably already weakened and exhausted condition of the child, and the chance of diffusing pus over the abdomen. 'Thus, in twenty-six of my cases, the appendix was not searched for, but was removed subsequently. When pus is already diffused throughout the abdominal cavity, flushing the peritoneum is decidedly contra-indicated. Accessible pus, however, may be mopped away and copious drainage provided through the original incision and through countes incisions. In "clean" cases, I employ a small gridiron incision, since it reduces the chances of a post-operative hernia to a minimum. The stump of the appendix must be carefully disposed of by tucking under, and cecoplication must be so performed that there will be no liability of the sutures yielding, thus permitting reinfection of the peritoneum by the stump. As a routine measure a glass tube should be passed into the pelvic basin to explore for fluid, lest a pelvic collection be overlooked, and this precaution may be rendered doubly effective by rectal examination previous to operation.

The post-operative treatment of appendicitis is highly important. 'This begins immediately on the patient's removal from the operating table. If drainage has been required, the patient should be propped upright in bed, in the Fowler position. I do not maintain this position for more than thirty-six hours, for fear the intestines, already crowded into the pelvis by gravity, adhere to each other and cause intestinal obstruction. Enteroclysis, I am sure, is most beneficial for pus cases.

Nausea, spitting up, and vomiting after operation, usually yield to the stomach-tube. If these are persistent, however, and if there is a sudden severe pain becoming paroxysmal, intestinal obstruction has developed, as these are the initial symptoms.

The classic symptoms of intestinal obstruction, projectile vomiting, great distention, and retention of feces and gas, must not be permitted to appear,. since they bring forlorn lope to the operating-table. These are not the symptoms of intestinal obstruction, but are those of a toxic peritonitis, the result of intestinal obstruction. I found the temperature and pulse to be of but little significance in these cases. When operating, if no definite constricting band is found, and the adhesions are numerous, the best procedure is to establish lateral anastomosis to circumvent the obstructed area. Accordingly, I established ileocolostomy in one of my cases of intestinal olstruction. In two other cases the same procedure was indicated at the primary operation for prophylaxis of the partial obstruction, which was present, becoming complete. In the one, two knuckles of jicum had adhered so as to produce partial obstruction by agglutination, and ileocolostomy was necessary. In the other, enterorrhaphy to close a perforation of the ileum so narrowed the intestine that ileocolostomy was likewise performed. I have prepared a table showing sixteen cases of intestinal obstruction operated on with one death, that of a boy, admitted on the fourth day of his illness, who had developed a friglitful peritonitis and, after a plucky fight of eighty-five days, in the course of which he developed bronchopneumonia and subphrenic absecss and endured three operations, finally succumbed to that octopus of surgery, universal abdominal adhesions.

Secondary abscess occurred in twelve of my cases, and was subphrenic in six. Cases showing diffuse peritonitis at operation must be watched carefully throughout the first month of the post-operative period for evidence of this complication. Protracted elevation of temperature, together with high leukocyte count and local signs, usually indicate secondary abscess. Subphrenic abscess fixes the diaphragm, produces rigidity of the overlying muscles, pushes the liver down, causes diaphragmatic pleurisy, and makes the patient profoundly septic. In the series of intestinal obstruction, two secondary abscesses were found, one beneath the diaphragm and the other at the duodeno-jejunal flexure.

The amount of urine must be watched daily after operation, and the stools examined for blood and intestinal parasites. 'The heart and lungs should be examined daily, and the skin closely watched for prompt diagnosis of the eruptive fevers and the throat for diphtheria. Six of my patients developed contagious diseases during their convalescence.

As regards drainage, I employ it only when the exudate is purulent or in large quantity. I use iruze, with or without a glass or rubber drainage-tube. 'The objection to drainage, especially with tubes, is that it may cause. inflammatory exudate predisposing to intestinal obstruction. Glass tubes are more suitable for the pelvis, but their rigidity is a drawback. One of my patients broke a glass tube in his pelvis. In three others the tube was found, when dressing, to be blocked by a plug of omentum. The glass tube is usually removed within three days, when the exudate becomes clear and small in amount. It is replaced by a rubber tube, which is removed within a week. Rubber tubes are also useful in draining puckets of pus through counter-incisions, and, in conjunction with gauze, for large collections. Gauze drains well for a few hours, but, after that, it is only protective in function and hinders, rather than favors, drainage. Over the drainage I place ganze dressings, wrung out in sterile salt solution, since thus they absorb discharges more readily than a dry dressing.

\section{CONCLUSIONS}

1. Appendicitis in childhood occurs with increasing frequency from birth to puberty, and is more common in males.

2. It runs a rapid and severe course in children more often than in adults. There is less tendency to the formation of strictures, but fecal concretions are more often found.

3. Enteric fever, intestinal catarrh and infiuenza may predispose to appendicitis. Other infectious or contagious diseases and nasopharyngeal troubles are hardly to be considered as etiologic factors.

4. In infants the symptoms of acute appendicitis are often scanty, irregular and misleading. Infantile appendicitis is more frequent than is generally believerl, or than statistics. In older children even more regularly than in adults, acute attacks occur suddenly and stormily. Chronic appendicitis represents a focus of chronic autotoxemia, with all its attending evils. 
5. All cases of abdominal trouble in children should be regarded as appendicitis until proved otherwise. Differential diagnosis must be made between appendicitis and intestinal catarrh or worms, right-sided pneumonia or sacro-iliac disease, ovarian cyst twisted on its pedicle, mesenteric cysts, cystitis and rectal abscess.

6. The prognosis in acute appendicitis is favorable, if the case is received early and if the appendix is removed early. If the patient is operated on within the first twenty-four hours, the mortality is practically nil. After this time, the prognosis rapidly becomes worse. In chronic appendicitis an acute attack with perforative nppendicitis is always to be feared.

7. 'The result of this ideal in treatment is to maintain the mortality at nil. Early operation is the normal course to pursue.

8. In intra-appendiceal appendicitis the appendix with the entire diseased tissue can be removed with nothing but benefit to the patient.

9. Non-operative treatment is indicated in cases of localizing abscess with diffuse peritonitis. Opium and purgatives are absolutely contra-indicated. Cathartics must never be given unless it is absolutely certain that appendicitis is absent.

10. Operation is even more suitable for children than for adults.

11. Post-operative treatment is highly important. The Fowler position must not be maintained for more than thirty-six hours in drainage cases; lest intestinal obstruction develop.

12. Intestinal obstruction is ushered in by sudden, severe pain, becoming paroxysmal, and by nausea, spitting up and vomiting. Iater symptoms arise in consequence of toxic peritonitis, the result, of intestinal obstruction. The temperature and pulse are of but little significance in these cases. In the presence of numerous adhesions ileocolostomy is the best procedure.

13. Secondary abscess must be carefully watched for. It is revealed by a rise and continued elevation of temperature, with high leukocyte count and local signs.

14. Contagious discases must be recognized at once.

15. Drainage is to be employed only when the exudate is purulent or in large quantity. By its presence, it produces adhesions and predisposes to intestinal obstruction. Glass tubes may be broken or plugged by omentum. Rubber tubes are valuable for their pliability. Gauze drains well at first, but later retards drainage. A wet dressing is the best for absorption.

\section{S'TATISTICS}

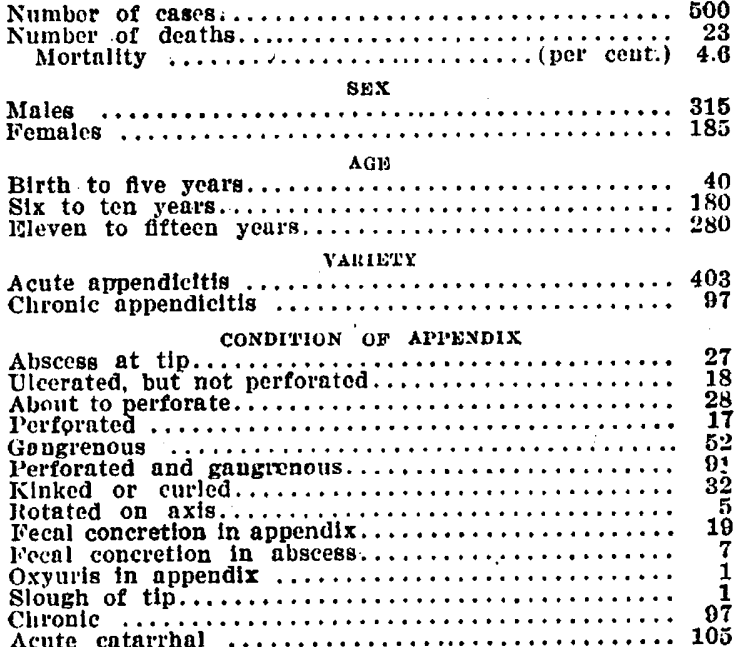

CoNDITION OF PERITONHUM

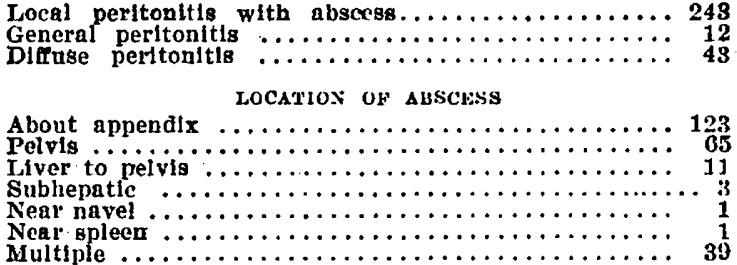

MISCbLlASWOUS PA'HOLOGIC CONDITIONS

Gangrene of liver (nartlal)

Gangrene of spleen (one-half)

Gangrene of omentum (partial)

Gangrene of cecum (single)

Gangrene of cecum (multiple)

Gangrene of lleum (Dartial)

Ecchymosis of cecum (subserous)

Cecum adherent to parletes.

'elforation of lleum.

Uterus didelphys

Uterus didelphys

on

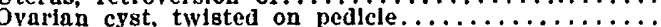

DRAINAGE

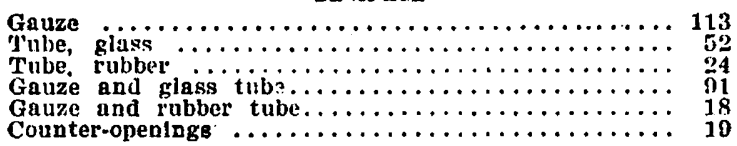

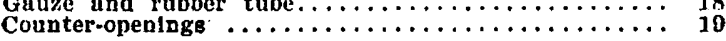
COMPLICATIONS

Bronchitis

I'necumonla

Abscess, seconda

Abscess: subphrenic

Phlebitis

I'arotitis

Nephritis

Endocal

Diphtberla.

Scarlatin

Pieasles

Pertussis

Wirsipelas

Melena.

IJemorrtrige, secondary

Ulcer, decubltus $\ldots \ldots \ldots \ldots \ldots \ldots \ldots \ldots \ldots \ldots \ldots \ldots$ CaUSB of Death

General peritonitts $\ldots \ldots \ldots \ldots \ldots \ldots \ldots \ldots \ldots \ldots$

Pneumonia

Uremla

Abscess. pertsplent.

Hemorringe, second

Gangrene of spleen.

Gangrene of fleum....

1534 North Fifteenth Street.

\section{ABSTRACT OF DISCUSSION}

Dr. L. S. MoMurtry, Iouisville, Ky.: The subject of appendi. citis has received such frequent and elaborate consideration in this section from year to year that it is diffeult to present any phase of the subject which lias not hitherto been discussed. The paper just read, however, bring forward an important and common incidence of this disease which has not had adequate attention. This disease is often overlooked in children, or the diagnosis made too late to obtain the best results from treatment. There are two conditions which render diagnosis exceptionally difficult: First, those anatomic variations found in clildhood relating to the position and relations of the caput coli and appendix, developmental in character, detract from the classic local symptoms and are in consequence mis leading. Second, in early childhood the patient. is unable to lend the coiperation as to subjective symptoms afforded by adults; which is so valuable ats a diagnostic aid. And again, the diagnosis is more difficult because in young children palpation is impracticable, especially deep palpation. Gentle rectal examination is a valuable aid to diagnosis, and will often dis close the nature of the disease.

'T he essnyist has properly emphasized the importance of quick work in the operative procedure. The dangers of prolonged 
anesthesia and extensive manipulation are inereased in operations in children, and hence the greatest expedition should be observed. In a large proportion of suppurative eases the appendix should not be searchea for, the surgeon contenting himself with evacuation and drainage for the immediate good result. In a word, Dr. Deaver has alvoented the same prin. ciples in eliildren that should be applied to adult life, ufter diagnosis has been established. In my experience intestinal obstruction is more common after operntion in children than in adults, and the early recognition of this sequel will do much to prevent a fatal result. The rule in diagnosis set forth by Dr. Deaver is an admirable one, and sliould be generally adopted, viz., that dingnosis of appendieitis should be assumed in eases of severe abdominal pain accompanied by fever, and, unless proved otherwise, should be treated as appendicitis. And finally, in acute inflammatory disease of the abdomen in children opium should not be given in the early stage of the disease. The use of opium and drastic cathartics is harmful and should be withheld.

Dr. Edgar A. Vander Veer, Albany, N. Y.: In my experience, based on a study of the cases occurring in the practice of my father and myself, I find that the disease is most general between the ages of ten and twenty. Before the age of ten years the cases are comparatively infrequent and not so easily dingnosed by the attending physician, because of the inability of the child to make known the exact location of the pain. The approach to and the commencement of puberty also seems to have a bearing on the subject, and may to some extent account for the increased number of cases recognized after the age of ten years.. Our youngest case occurred in a boy, three and one-half years old, who was ill only six hours, but from whom a gangrenous appendix was removed. He complained of pain in the stomach, but the diagnosis was made chiefly on the rigidity of the right rectus muscle.

As the author says, a child often comes to the surgeon with a history of having had bilious attacks, and when such a history is given it is wise to entertain the possibility that there have been attacks of appendicitis. In fact, I have operated in scveral cases in which the only symptom complained of was an indefinite pain in the abdomen, accompanied by a history of the patient having had several bilious attacks, and invariably have found a diseased appendix to be the cause of the trouble. Diferential dingnosis between appendicitis and the other conditions mentioned is not very ensy, though very important, and can only be determined by a careful weighing of the symptoms.

When we obtain a history of a child having suffered for years from bilious attacks, taken suddenly with vomiting and an acute pain in the abdomen, no matter whether in the right inguinal region or not, but gradually converging to that point, with an incrensed leukocytosis and with rigidity of the right rectus muscle, without excluding any of the other conditions, we are safe in making a diagnosis of appendicitis.

As to the laboratory as an aid in diagnosis and prognosis, I have not found it of very much value, as the decision must be navie by the surgeon on the symptoms presenting at the time he sees the case, not delaying for an elabornte report from the laboratory, which delay might prove fatal in many instances. Of course, the most favorable time for operation is in the first twenty-four hours, when the prognosis is very good indeed; but it is seldom that we see a case under such favorable conditions; it usually runs along anywhere from three to four dnys to a week. In all these crses I belicve in immediate oper. ation, no matter whether the appendix has not as yet ruptured, whether the absecss has formed, or whether there is diffuse peritonitis present. Often in cases in which the patients are in desperate condition $I$ have seen them recover after operation, and in my opinion the prognosis lies not so much in the operation as in the postoperntive treatment.

The average practitioner within the past five years has come to recognize the symptoms of appendicitis much earlier than formerly, the result being that cases come to operation much sooner and the danger of resulting complications is greatly lessened, so that the abseess cases and cases of general peritonitis, with their consequent complications, are also greatly lessened in number.
Children, as a rule, ract quiclily after operation and seem to have more resisting power against infection, etc., than people of middle age.

When we come to look over the entire situation, appendicitis, barring the difficulty of making dingnosis, is no different in children from what it is in tulults.

Dir. M. M. Jucin, Cortland, N. Y.: Why can we not treat appendicitis as we generally trent other things, strictly on a busis of facts? In other words, why not believe what we see, and strive to be prepared to rend the handwriting on the wall-on the inside of the abdominal wall-from external manifestations, and not be misled by irrelevant symptoms? It las been my experience ns well as that of several surgeons to operate on patients wilh acute, progressive appendicitis who were ill in bed with other unassocinted ailments.

Much as we have learned about appendicitis, we have yet to learn that we ought to treat it precisely as we treat cancer, that is, as a local disease. To wait for the development of constitutional symptoms, such as elevation of temperature, increased frequency of pulse, with high tensionthe development of tympanites, ete., is to trifle with death in defiance of the plainest teaching of experienced surgeons. Our ablest surgeons, whose experience covers many thousand cases, tell us that the actual pathology of the appendix is not reflected by the symptoms of the patient. Why then should the general practitioner presume on a limited degree of good fortune, often mistaken for skill, decide offhand what cases are operable und what inoperable, without recourse to a surgical consultation? Mennwhile let it be armitted that good medical trentment is fur preferuble to poor surgical treatment.

Appendicitis may oceur in any section of the country, at any time, and in any individual. There is but one treatment for a progressive case of appendicitis, namely, operation, not when fulminating peritonitis has developed, but long before the deadly infection has passed beyond control.

Some laymen, and many physicians "dread operations" having in mind operations performed too late and under conditions which they do their best to perpetuate. 'They do not recommend operation except as a last resort, life or deathunfortunately, such patients usually have both operation and death. We are deeply indebted to Morris, Fowler, Ochsner, Murphy, the Mnyos, and a score of others, for their thoroughgoing studies of the trentment of peritonitis. Surgical prophylaxis is the watchword for the early trentment of suppurative peritonitis-just as one fire.proof building is worth a dozen fire engines. It is fair to assume that within a few years, the man who trifles with a ense of progressive appendicitis will be classed with the one who applies a grensy nostrum to a mammary cuncer.

Dr. Maurtce Rosentilat, Fort Wnyne, Ind.: As has been brought out by the paper, as well as in the discussion, the lack of drainage and the formation of adhesions with consequent intestinal obstruction have contributed to the immediate mortality in these cases. I attribute nearly all my mortality in appendicitis to obstruction and lack of drainnge. You can prevent bowel adhesions, at least for some time, by the liberal application of petrolatum. Like paraflin, petrolatum is absorbed very slowly, possibly not at all. By applying it in the area to be drained, I have found that drainage is more prolonged and more profuse, and that the dangers of adhesions and obstructions can be greatly reduced thereby. I lave used petrolatum by manual application to a limited area, in a few cases-the last four cases, I think, in which I operated. I got better drainuge, more efficient drainage, and more prolonged drainnge, and probably uverted some of the dangers of adhesions from obstruction.

Dr. Heranan TUnolske, St. Louis: There are without question certain principles thoroughly understood and known which govern the management of appenclicitis in children. No one lias done so much in this direction as Dr. Ochsner. We have learned considerable about the proper trentment of appendicitis from him. There are some things that are very clear today. Some twenty-odd years ago, when I had a very limited experience in operating for appendicitis, I said: "Make the diagnosis and then operate." I have several times since then changed my opinion, but have always come back to the orig. 
inal idea. The point of greatest importance is that $n$ diag. nosis of appendicitis should not be based on any one symptom. There is no such thing as a pathognomonic symptom of appen. dicitis. Pain in the region of the appendix niny mean something else. Not long ago a physician made $a$ diagnosis of appendicitis for a man who was triveling in the East and urged immediate operation. The patient returned to St. Iouis at once, suffering great pain at the classical point. He asked me to operate for nppendicitis. I had him go to bed in the hospital. When I saw him in the morning, there was as beantiful a strenk of herpes zoster ns I lave ever seen, occupying the line of pain. Recovery was prompt.

As to trentment, I belicve in operation as soon as the diagnosis is made, unless there is a positive contraindication. In making a diagnosis we must be on our guard, because in the early hours in young elildren there may be something else brewing. I have seen three cases recently, in which I was called by competent internists to operate, and which occurred in children of five and six years, who within a day developed pheumonia. One of them was rolling around in bed moving his limbs freely. I examined the child and elicited no pain in the abdomen. I asked for ten hour's deliny, and at the end of that time the doctor told me the child had an ummistakable attuck of pneumonia. First, muke n cureful diagnosis and then act, but never laurbor the iden that appendicitis patients do not die; nor should you operate on the strength of one symptom or a combination of indistinct symptoms.

When you are sure of your dingnosis and the patient is still in fair condition, operate at once. If you wait until pus is forming, then you must follow some other plan of treat. ment and use your best judgment in selecting the proper time for operation later in the interval. An appendix which has been inflamed must be removed some time.

DR. Jorn B. Deaver, Philadelphia: We have heard a great deal about race suicide within the last few years from one of our most distinguished citizens, but there is no one thing that contributes so largely to a decreasing population as does sterility, the result of pelvic appendicular peritonitis in young girls and young women.

\section{PIRSISTENT PATENCY OF THE DUCTUS ARTERIOSUS}

Dhgenteration of the CARDIAC MUSCLE AND CORONARY Al'IERIES, $A$ ND OF THE SINO-AURICULAR BUNDLE, FOLLOW BSD RUPTURE OF THE RIGHT VEN'TRICLE*

\section{KATE CAMPBELL, MEAD, M.D.} MIDJLLETOWN, CONN.

One of the most interesting problems of physiologists to-day is concerned with the structure and action of the leart. So much experimental work has been done during the past few years on the cardiac muscle, nerves, valves, and blood supply, as well as on the arterial system, by means of measuring apparatus and surgical operations, that any extraordinary case of heart failure which can be studied during life and post-mortem should be made available for future reference, as an addition to our sum-total of knowledge of coligenital anomalies, as well as of inflammatory disease.

It is for this reason that I have ventured to make a slight contribution to the literature on congenital cardiac malformation, which in this case was associated with a sequence of disorders of the heart and its valves, l'esulting in a rare condition of rupture of the right ventricle, and in the patient's death at the age of 26 .

In presenting this report I must express my regret that no sphygmographic tracings or electrocardiograms

* Tead In the section on Irnctice of Mealicine of the American Madical Associnilon, at the sixty-first' Anuual Sesslon, held at $\mathrm{St}$. Ionis, Juue, 1010 . were made from the heart, the arteries, or the veins; but a brief study of the conditions as a whole may not be unprofitable, although a full discussion of such a case would far exceed the limits of this paper.

\section{REPORT OF CASE}

Ilistory-The patient was a married woman. Of her early history there is little known; she told me she had always had rheumatism and backacle, had suffered frequently from grip, and that her physicians in Berlin, Germany, said she had heart trouble since she was a little girl. IIer parents and grandparents were healthy. I first saw her April 3, 1905, and her condition was as follows: Height, about 5 feet, 4 inches; weight, 120 pounds; body, plump; color, good; some ane on face; catarll of throat and nose; lateral and anterio. posterior curvatures of the spine due to muscular weakness, simulating both scoliosis and kyphosis; nortic pulsation in the abdomen noticeable; heart enlarged $1 \mathrm{~cm}$. to right and left, with a murmuring, noisy systolic murmur heard both at base and apex, extending to right of the sternum and almost to the axilla; lungs normal; bowels distended with gas; diarrhenl movements; stomach larger than normal; liver normal; left kilney in left groin; pelvic organs normal; urine normal.

After a summer of rest and hygienic life the cardiac murmurs neurly disappeared, but the patient continued to suffer from backiche, diarrhea, and entarrh of the throat. The following yenr she went through a suceessful pregnancy in better heulth than usual, even omitting colds and grip. During the summer of 1907 she had a nervous strain which was followed in the early autumn by a condition of flabby muscles and flabby heart, with loud systolic murmur over the pulmonary artery in the third space, and a strong thrill felt over the third and fourth interspaces at the right of the sternum, and frequent palpitations. Her intestinal indigestion was very troublesome, and the facial acne most annoying. Hygienic treatment, baths, massage, careful diet, and occasional doses of codein gave considerable relief, while digitalis, even in minute doses, eaused most uncomfortable bounding and beating of the arteries all over the body.

At the end of December, 1907, I referred the patient to Dr. Thayer of Baltimore, who sent me the following diagnosis:

"'llhere is evidently a congenital malformation, but one which from her history and condition, may well be compatible with a long life. The long machinery murmur over the right ventricle with systolic accentuation, together with the accentuation of the second pulmonic sound, and the rather large right side suggest a septum defect (ventricular). This lesion is also more compatible with long life than most other cardiac defects. A striking feature of this case is the fact that the murmur is so loud at the base and in the first left interspace, and that the accentuation high up is late, a late systolic, almost a dinstolic accentuation, but the murmur still continues throughout both cycles of the heart with the henrt sounds heard, as it were, superimposed. 'The loudness of the murmur high up and the change in its accentuation would suggest to me an open ductus arteriosus." 1

1. I have taker the following notes from Dr. Thayer's memoranda: "Welght, 121 1/2. Color is good. General nourishment good. I'ulse, 21 to the quarter at the beginning of examinntion regular. Radial, not palpable Pressure, by estimate, 120-28, mensurement, maximum, about 1i5: mlnimum not easy to estimate. Thorax, symmetrical Costal angle about 90 Movements, equal. Resonance and respiration clear in front. Back perfectly clear. Heart, ${ }^{2}$. M. 1. In the fifth space, approximately normal position 8.6 cm. from the median line, begins nbove in the second space and extends about $5.5 \mathrm{~cm}$. to the right of the medinn line in the fourth space. No thrill in the precordial region, nlthough the impulse is rather well felt in the second and third left spaces. Sounds, at the apex, flrst clear excepting for a soft systolle gradually fading awny. Second, clear, followed by a very soft diastolic. As one renches the fourth space $n$ characteristlc long machinery sound with systolic accentuntion lasting through the whole cycle is audible. Thls lo loudest in the thled space, well henrd in the second, also over the Piglit side and out over the left chest. In the first left space under the clavicle the murmur was also very long and wel lieard with late systolic or. perhaps, even diastolic accentuation. The secoud pulmonic is loud and sharp. The second aortic is also of falrly good Intensity. Might ktiney descends below the costa margin. Liver is fust felt descending below the costal margin on deep Inspliation; no enlargement. From the charncter and position of the murmur one is justlfied in assuming a septum defect. and from the murmur which is heard up under the clavicle in so high: a position, an open ductus Botalli." 